'Laboratory of Molecular and Chemical Biology of Neurodegeneration, Brain Mind Institute, School of Life Sciences, Ecole Polytechnique Fédérale de Lausanne, $\mathrm{CH}-1015$ Lausanne, Switzerland. ${ }^{2}$ Department of Neurosciences, School of Medicine, University of California at San Diego, La Jolla, California 92093, USA.

${ }^{3}$ Department of Pathology,

School of Medicine, University of California at San Diego, La Jolla, California 92093, USA.

Correspondence to E.M. e-mail:emasliah@ucsd.edu doi:10.1038/nrn3406

\title{
The many faces of $\alpha$-synuclein: from structure and toxicity to therapeutic target
}

Hilal A. Lashuel', Cassia R. Overk², Abid Oueslati' and Eliezer Masliah ${ }^{2,3}$

Abstract | Disorders characterized by $\alpha$-synuclein ( $\alpha$-syn) accumulation, Lewy body formation and parkinsonism (and in some cases dementia) are collectively known as Lewy body diseases. The molecular mechanism (or mechanisms) through which $\alpha$-syn abnormally accumulates and contributes to neurodegeneration in these disorders remains unknown. Here, we provide an overview of current knowledge and prevailing hypotheses regarding the conformational, oligomerization and aggregation states of $\alpha$-syn and their role in regulating $\alpha$-syn function in health and disease. Understanding the nature of the various $\alpha$-syn structures, how they are formed and their relative contributions to a-syn-mediated toxicity may inform future studies aiming to develop therapeutic prevention and intervention.

Lewy body diseases (LBDs) are a heterogeneous group of disorders that include Parkinson's disease (PD), PD with dementia (PDD) and dementia with Lewy bodies (DLB) ${ }^{1}$. Together, these diseases affect over 5 million people worldwide. LBDs are mainly characterized pathologically by the progressive accumulation of the presynaptic protein $\alpha$-synuclein ( $\alpha$-syn) - hence they are often referred to as synucleinopathies - and by the degeneration of neocortical, limbic and nigral-striato circuitries $^{2,3}$. A pathogenic role for $\alpha$-syn in these disorders is supported by various genetic data. Multiplications of the gene encoding $\alpha$-syn $(S N C A)^{4}$ and various point mutations in this gene (A53T, A30P and E46K) ${ }^{5-7}$ result in dominant familial parkinsonism. Moreover, certain polymorphisms in SNCA are major risk factors for sporadic $\mathrm{PD}^{8}$.

An increasing body of evidence from animal models as well as data from genetic, biochemical and biophysical studies support the hypothesis that the processes of $\alpha$-syn oligomerization ${ }^{9,10}$ and fibril growth ${ }^{11,12}$ have central roles in the pathogenesis of PD and other synucleinopathies $^{13}$. In addition, it is possible that the $\alpha$-syn monomers might also have a role in synucleinopathies by their displacement from their physiological location, resulting in a loss of cellular function, or by disrupting the activity of other molecular or signalling pathways ${ }^{14}$. Nevertheless, the molecular mechanisms by which a-syn aggregation contributes to neurodegeneration, the nature of the toxic forms of $\alpha$-syn and the cellular pathways that are affected by $\alpha$-syn remain unknown. Addressing these knowledge gaps will be crucial for understanding the molecular basis of synucleinopathies, developing tools to diagnose and monitor the progression of these diseases, and assessing the effectiveness of preventive and therapeutic strategies. Here, we provide an overview of the current state of knowledge regarding the role of $\alpha$-syn aggregation states in regulating $\alpha$-syn function under physiological and pathophysiological conditions. We also discuss the implications of these findings for therapeutic interventions.

\section{Physiological function of $\alpha$-synuclein}

Although the normal function (or functions) of $\alpha$-syn remains unknown, its localization at presynaptic terminals ${ }^{15-17}$ (FIG. 1a,b), its association with the distal reserve pool of synaptic vesicles ${ }^{18-20}$ and the deficiencies in synaptic transmissions observed in response to knockdown or overexpression of $\alpha$-syn suggest that $\alpha$-syn has a role in the regulation of neurotransmitter release, synaptic function and plasticity (FIG. 1c).

Snca-knockout mice exhibit an impairment in hippocampal synaptic responses to prolonged trains of high-frequency stimulation that deplete the docked and reserve pool of synaptic vesicles, as well as impairments in replenishment of docked pools from the reserve pool, indicating that $\alpha$-syn may control the refilling and the 
Lewy body

An intraneuronal globular inclusion composed primarily of $\alpha$-synuclein fibrils. Lewy bodies are characteristically found in Parkinson's disease although they are also detectable in other neurodegenerative diseases, such as dementia with Lewy bodies

\section{Fibril}

Mature fibrils are characterized by the following characteristics a cross- $\beta$-sheet $X$-ray fibre diffraction pattern; $\beta$-sheet-rich circular dichroism and Fourier transform infrared spectroscopy (FTIR) spectra; binding to Congo red and Thioflavin-T/S; and a characteristic filamentous morphology $(8-12 \mathrm{~nm}$ in diameter and $>1 \mu \mathrm{m}$ in length), as revealed by atomic force microscope and transmission election microscope imaging. $\alpha$-synuclein can form fibrils of diverse morphologies depending on the solution conditions.

a
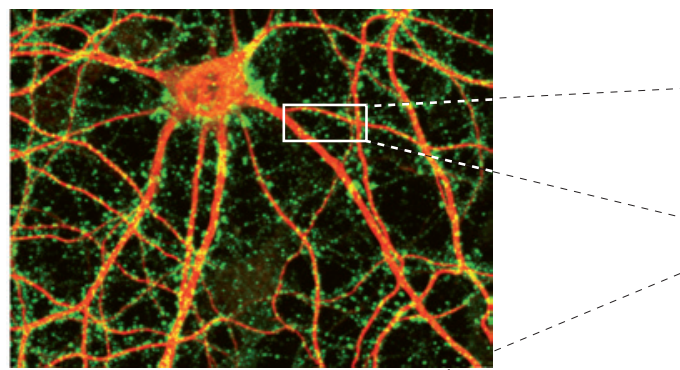

b

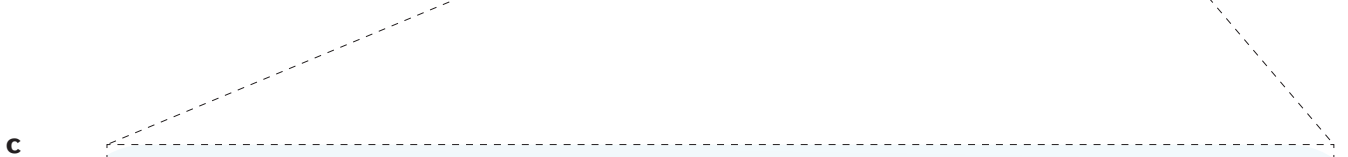

C

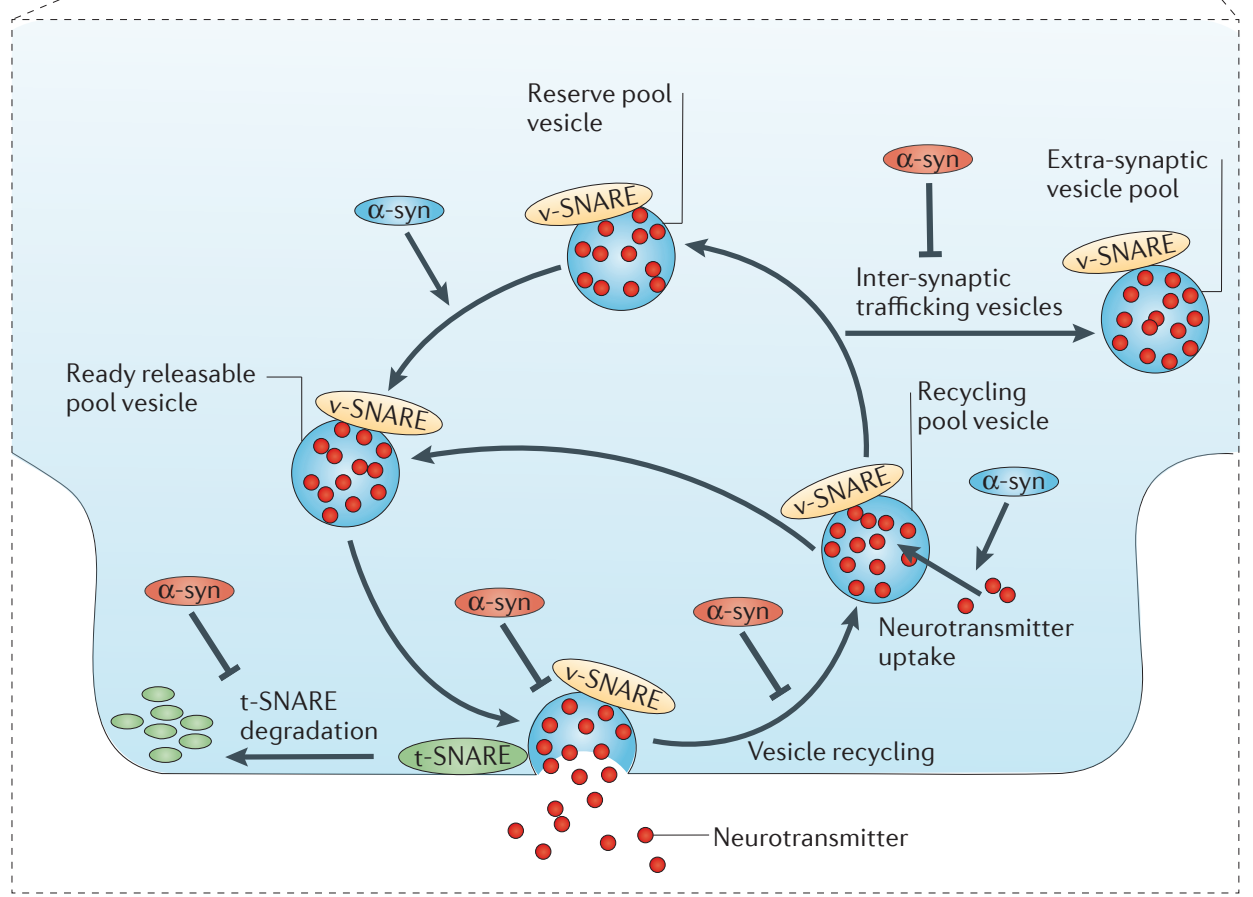

Figure 1 | Functional properties of $\boldsymbol{a}$-synuclein. a,b | Wide field (a) and magnified (b) images of cultured cortical neurons from a postnatal day 1 wild-type mouse. A neuronal dendrite (as revealed by MAP2 immunostaining; red) is shown opposed to $\alpha$-synuclein ( $\alpha$-syn)-positive presynaptic densities (green), indicating that $\alpha$-syn is located in presynaptic terminals. c|This schematic highlights the roles of $\alpha$-syn at the presynaptic terminal in the regulation of vesicle trafficking and vesicle refilling ( $\alpha$-syn; blue), as well as the interactions between target membrane-associated SNARE (t-SNARE) and vesicle-associated SNARE ( $v$-SNARE) proteins and neurotransmitter release. Accumulation of $\alpha$-syn induces an impairment of neurotransmitter release, vesicle recycling and trafficking between synaptic buttons and influences the stability of t-SNARE complex assembly ( $\alpha$-syn; red). Depletion of $\alpha$-syn induces an impairment of vesicle trafficking between the reserve pool and the ready releasable pool and a deficiency in vesicle refilling and neurotransmitter uptake (not shown).

trafficking of synaptic vesicles from the reserve pool to the site of synaptic vesicle release ${ }^{21,22}$. Moreover, depletion of $\alpha$-syn, through the use of antisense oligonucleotides, induces a decrease in the availability of reserve synaptic vesicle pool in primary cultured hippocampal neurons ${ }^{23}$.

Transgenic mice overexpressing human $\alpha$-syn exhibit impairment in synaptic vesicle exocytosis and a reduction in neurotransmitter release ${ }^{24-26}$. Similar effects have been observed after $\alpha$-syn overexpression in genetic rodent models of $\mathrm{PD}^{27,28}$ and in the PC12 stable cell line ${ }^{29}$. At the ultrastructural level, overexpression of a-syn induces a decrease in readily releasable vesicles ${ }^{27}$ and affects the recycling of synaptic vesicles following endocytosis, inducing a reduction in the size of the synaptic vesicle recycling pool ${ }^{26}$. Moreover, excess $\alpha$-syn induces a reduction in dopamine reuptake in dopaminergic terminals ${ }^{28}$ and inhibits intersynaptic trafficking of vesicles, leading to a smaller reserve pool of vesicles ${ }^{30}$

The possible role of $\alpha$-syn in regulating synaptic homeostasis is not exclusively related to its direct interaction with synaptic vesicles. $\alpha$-syn interacts with synaptic proteins controlling vesicle exocytosis, such as phospholipase D2 (REF. 31) and the family of RAB small GTPases $^{32}$. Recent studies reported that $\alpha$-syn can act as 


\section{SNARE}

Soluble NSF

( $N$-ethylmaleimide-sensitive

factor) attachment protein

(SNAP) receptor.

\section{Oilgomer}

Oligomers comprise a number

of smaller, identical units

(monomers). In the context of

$\alpha$-synuclein oligomers, this

term encompasses a wide

range of species, ranging from

low-molecular-weight species

(including dimers, trimers and tetramers) to high-molecular-

weight species (such as

spherical, chain-like and

annular structures. a chaperone protein for the presynaptic SNARE protein complex by controlling the degradation and affecting the assembly, maintenance and distribution of this complex (FIG. 1C), which is directly implicated in the release of neurotransmitters, including dopamine ${ }^{33}$. Together, these observations indicate that $\alpha$-syn has an important role in the trafficking of synaptic vesicles and in the regulation of vesicle exocytosis, and may contribute to more subtle regulatory phenomena by controlling synaptic homeostasis-associated proteins.

The fact that the individual synuclein knockouts ( $\alpha$-, $\beta$ - and $\gamma$-syn) are viable suggests that synucleins are not essential components of the neurotransmitter release machinery but may contribute to the long-term regulation and maintenance of nerve terminal function ${ }^{34}$. The neuroprotective effects of $\alpha$-syn against progressive neurodegeneration in mice deficient in cysteine-string protein- $\alpha$ $(\mathrm{CSP} \alpha \text {; also known as DNAJC5) })^{35}$ strongly suggest that its functional properties become more prominent or essential under conditions of stress. The neuroprotective function of $\alpha$-syn appears to be mediated by its ability to bind to membranes and vesicles, as the A30P a-syn mutant, which is deficient in membrane binding, failed to show protection in CSPa gene-knockout mice.

\section{Structure of $\boldsymbol{\alpha}$-synuclein}

Because a protein's sequence and structure are linked to its function, a concerted effort has been made to characterize the sequence and structural determinants that govern the cellular properties of $\alpha$-syn and its aberrant behaviour in PD and other synucleinopathies. $\alpha$-synuclein is a $14 \mathrm{kDa}$ protein ( 140 amino acids; $\mathrm{p} K_{\mathrm{a}}$ of $4.7)^{36}$ that is characterized by an amphipathic lysine-rich amino terminus, which has a crucial role in modulating its interactions with membranes, and a disordered, acidic carboxy-terminal tail, which has been implicated in regulating its nuclear localization and interactions with metals, small molecules and proteins ${ }^{37,38}$ (FIG. 2a). The central region of $a$-syn was first purified from amyloid plaques in patients with Alzheimer's disease $(\mathrm{AD})^{36,39}$. It contains a highly hydrophobic motif that comprises amino acid residues 65-90 and is known as the non-amyloid- $\beta$ component of $\mathrm{AD}$ amyloid plaques $(\mathrm{NAC})^{36,40,41}$ (FIC. 2a). The NAC region is indispensable for a-syn aggregation; the deletion of large segments within this motif greatly diminished $\alpha$-syn oligomerization and fibrillogenesis in vitro ${ }^{42,43}$ and in a cell-based assay ${ }^{44}$.

Studies by several groups using different biophysical methods (for example, NMR, light scattering and circular dichroism) consistently showed that a-syn purified from Escherichia coli under native or denaturing conditions exists predominantly as stable unfolded monomers ${ }^{38,45}$. When $\alpha$-syn was extracted from patients diagnosed with LBD and age-matched controls and evaluated by non-denaturing gels or size exclusion chromatography (SEC) columns, $\alpha$-syn monomers migrated as $57-60 \mathrm{kDa}$ proteins, but in denaturing gels they migrated as $14 \mathrm{kDa}$ proteins $\mathrm{s}^{42,44}$ (FIG. 2b). Initially, the apparent size of $\alpha$-syn in native gels and SEC led many researchers to propose that this protein exists as a stable oligomer, but subsequent detailed biophysical studies demonstrated that the larger than expected size is mainly due to the fact that monomeric $\alpha$-syn adopts an unfolded, extended conformation ${ }^{45,46}$, which results in a larger than expected hydrodynamic radius (BOX 1).

The apparently multifunctional properties of $\alpha$-syn may lie in its conformational flexibility, which may allow the protein to adopt different conformations upon interacting with biological membranes of different compositions, other proteins or protein complexes ${ }^{47,48}$. It is well established that $\alpha$-syn adopts an $\alpha$-helical conformation upon binding to synthetic or biological membranes in vitro ${ }^{38}$. However, very little is known about the conformational state (or states) of $\alpha$-syn in the different compartments of the living cell, and there is a lack of direct evidence for a functional role of native $\alpha$-syn oligomers in biological membranes. It is conceivable that native $\alpha$-syn exists in equilibrium between different conformational and/or oligomeric states. Several factors, including oxidative stress ${ }^{49}$, post-translational modifications $s^{50,51}$, proteolysis ${ }^{52,53}$ and the concentrations of fatty acids ${ }^{5-56}$, phospholipids and metal ions ${ }^{11,49}$, were shown to induce and/or modulate $\alpha$-syn structure and oligomerization in vitro, and these factors may influence this equilibrium between the monomer and oligomer state in vivo. Together, these studies suggest that $\alpha$-syn exists predominantly as a monomer, but do not rule out the possibility that it can form a stable multimer and/or adopt different structures under specific stress-induced conditions or upon interaction with other proteins, specific ligands, lipids and/or biological membranes. Understanding the molecular determinants that regulate the conformational and oligomeric states of native $\alpha$-syn and the structural basis of its toxicity will be crucial for our ability to generate and test different mechanistic models and hypotheses of $\alpha$-syn function in health and disease. Gaining this knowledge will also have important implications for the development of therapeutic strategies based on targeting a-syn, as discussed in the following section.

\section{a-synuclein and disease}

Paths to increased expression and accumulation of $\alpha$-synuclein. PD, DLB and other LBDs show accumulation and redistribution of $\alpha$-syn in various brain regions and cellular populations. These changes in the nature and localization of $\alpha$-syn may have pathogenic roles in these disorders (FIG. 2c) and can be reproduced in $\alpha$-syn transgenic animal models $\mathrm{s}^{1,3,57-59}$ (FIG. 2d).

The levels of $\alpha$-syn in the CNS depend on the balance between the rates of $\alpha$-syn synthesis, aggregation and clearance ${ }^{60}$ (FIG. 3a,b). An imbalance between these mechanisms, caused by dysfunction of one or more of these pathways, can result in abnormal levels of $\alpha$-syn that might favour the formation and/or accumulation of oligomeric and fibrillar species, which may be toxic. Indeed, in some familial forms of parkinsonism, multiplication of SNCA results in increased accumulation a-syn because of increased protein expression ${ }^{4}$, whereas in others, SNCA mutations enhance the propensity of a-syn to aggregate ${ }^{9}$ (FIG. 3a). A genome-wide association 


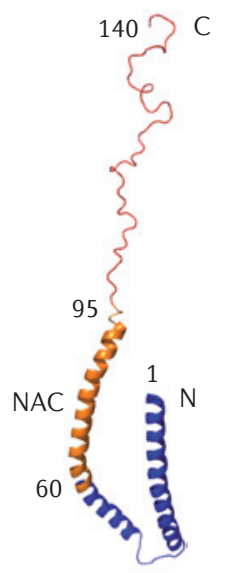

b

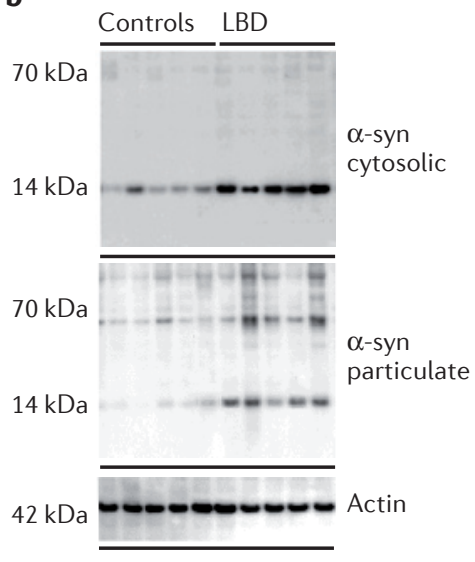

C
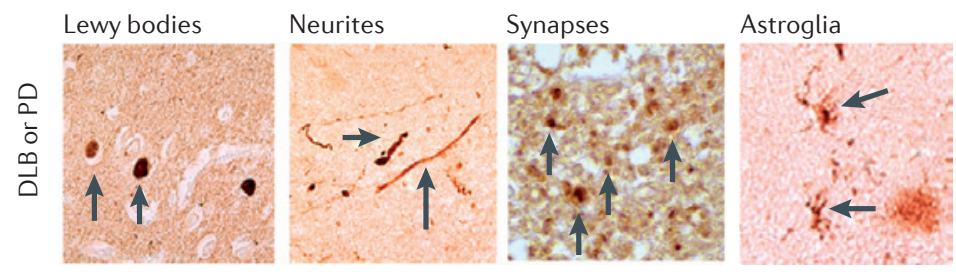

d
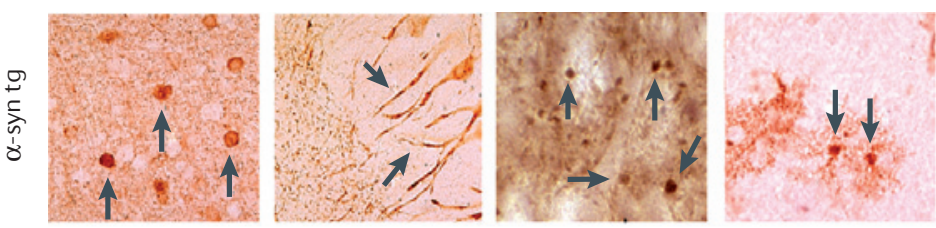

Figure 2 | Biochemical structure of $\alpha$-synuclein and its pathological distribution in Parkinson's disease, and a mouse model of Lewy body disease. a Schematic representation of micelle-bound $\alpha$-synuclein ( $\alpha$-syn; Protein Data Bank ID: 1XQ8) ${ }^{37}$. The $\mathrm{N}$-terminal region, the non-amyloid- $\beta$ component of Alzheimer's disease amyloid plaques (NAC) region and the C-terminal part are coloured blue, orange and red, respectively. Numbers refer to amino acid residues flanking the different regions. b | Western blot identifying $\alpha$-syn in brain homogenates from control and Lewy body disease (LBD) cases that were divided into cytosolic and particulate fractions. $\alpha$-syn migrated to $57-60 \mathrm{kDa}$ as well as to $14 \mathrm{kDa}$ in the particulate but not cytosolic fraction owing to the different conformational states of the protein. $\mathbf{c}, \mathbf{d} \mid \mathbf{\alpha}$-syn is present in Lewy bodies, neurites, synapses and astroglia in dementia with Lewy bodies (DLB) and Parkinson's disease (PD) and in transgenic ( $\mathrm{tg}$ ) mice overexpressing human wild-type $\alpha$-syn (known as PDGFB-human wild-type $\alpha$-syn mice), as indicated by arrows.

study (GWAS) showed that individuals with certain variations in the SNCA gene had a higher risk of $\mathrm{PD}^{61}$. One such polymorphism is known as Rep1, which occurs in the promoter region of SNCA and might increase the susceptibility to PD by increasing the expression of $\alpha$-syn ${ }^{62}$. Clearance of $\alpha$-syn monomers and aggregates occurs via direct proteolysis (for example, by neurosin or matrix metalloproteinase 9 (MMP9) $)^{63}$, binding to molecular chaperones (for example, heat shock proteins (HSPs) $)^{64}$, the proteasome ${ }^{65-67}$ and autophagy (involving the activity of the lysosome $)^{60,68-70}$ (FIG. 3a). In sporadic forms of PD and DLB, failure of the autophagy pathways to eliminate oligomers might enhance $\alpha$-syn-mediated toxicity $^{69}$ (FIG. 3a). Chaperone-mediated autophagy ${ }^{68}$ has been shown to be disrupted by oligomeric forms of wild-type and disease-associated mutant $\alpha$-syn. In PD and DLB, the levels of key autophagy molecules such as ATG7, a ubiquitin-like modifier-activating enzyme, and mammalian target of rapamycin (mTOR), a serine/ threonine protein kinase, are dysregulated ${ }^{71}$.

Evidence for different conformers of $\alpha$-synuclein in disease. There are a number of different $\alpha$-syn conformers, including oligomers, protofibrils and fibrils, that have been associated with the pathogenesis of LBDs. The fibrillar forms of a-syn are detected mostly in Lewy bodies $^{72,73}$, which are localized in the neuronal cell body. These intracellular structures are the neuropathological hallmark of PD and DLB (FIG. 2b) and are thought to reflect an attempt by the neurons to isolate and/or convert toxic $\alpha$-syn oligomers to fibrils, which are stable, less dynamic structures that exhibit reduced toxicity. Aggregates of $\alpha$-syn can also be observed in astroglial cells from cases of $\mathrm{LBD}^{74}$. The distribution of $\alpha$-syn pathology in human diseases can be recapitulated in a-syn transgenic mice ${ }^{75}$ (FIG. 2c).

Strong indirect evidence supports the existence of various oligomeric a-syn species in vivo under pathophysiological conditions. SDS-resistant dimers as well as low- and high-molecular-weight oligomeric forms of $\alpha$-syn have been detected in diseased human brains ${ }^{10,76,77}$ and in brains of transgenic animal models of synucleinopathies ${ }^{10,18,78}$ that express wild-type or PD-associated mutant variants of $\alpha$-syn ${ }^{79}$ (FIG. 2a). In contrast to fibrillar a-syn, oligomeric aggregates are most likely to be located in axons (FIG. $1 \mathrm{~b}$ ) and presynaptic terminals, where they might damage synapses and dendrites ${ }^{25,26,28,80-82}$.

In vitro, several oligomeric species of different morphologies, including spherical, chain-like and annular oligomers, have been observed before $\alpha$-syn fibril formation $^{83}$ (FIC. 4). The various oligomeric species seem to exist in equilibrium with monomeric $\alpha$-syn and undergo a very slow conversion to fibrils in the absence of a high molar ratio of monomers to other species of $\alpha$-syn (FIG. 4). However, the relationships between the various $\alpha$-syn oligomeric species and mechanisms of the inter-conversion between these different oligomers remain poorly understood, although some studies suggest that the formation of ring-like oligomers is not on the pathway to amyloid formation. Of note, both in vitro and animal model studies show that three PD-linked SNCA mutations (A30P, E46K and A53T) accelerate a-syn oligomerization, but only two of these (E46K and A53T) enhance fibrillization in vitro and in vivo ${ }^{9,42,84}$. Although the $\mathrm{A} 30 \mathrm{P}$ mutation has been shown to result in enhanced $\alpha$-syn fibrillization in vivo, as illustrated by an autopsy case of a patient with this mutation who had extensive Lewy body pathology ${ }^{61}$, in vitro it exhibits reduced fibrillization compared with the wild-type protein and other mutants.

Biophysical and SEC studies suggest that $\alpha$-syn SDSresistant oligomers from post-mortem human and transgenic animal brains can be in general divided into small ( 2-5-mers), medium ( 5-15-mers), and large ( 15-150-mers) oligomers ${ }^{85,86}$. Spherical oligomers $2-6 \mathrm{~nm}$ in diameter may be the toxic forms of $\alpha$-syn, as they promote neuronal degeneration and abnormal calcium currents in cultured primary cortical neurons ${ }^{86}$. 


\section{Box 1 The native state of $\alpha$-synuclein}

The wide distribution and abundant expression of $\alpha$-synuclein ( $\alpha$-syn) throughout the brain have been difficult to reconcile with its unfolded structure, which is expected to make the protein more susceptible to proteolysis and degradation. Thus, it was proposed that the oligomerization of $\alpha$-syn or its association with other proteins might represent mechanisms by which the protein may acquire different structures and functions in vivo. Two recent studies reported that native $\alpha$-syn exists as a folded tetramer ${ }^{126,127}$. The first study showed that $\alpha$-syn purified from mammalian cell lines or red blood cells exists as a stable $\alpha$-helical tetramer with an apparent size of 58-60 kDa, as was discerned by size exclusion chromatography (SEC), native PAGE (clear and blue-native PAGE) and sedimentation equilibrium studies ${ }^{126}$ The second study used NMR, chemical crosslinking and SEC, and indicated that $\alpha$-syn produced in Escherichia coli exists as a 'dynamic tetramer' that is rich in $\alpha$-helical structure ${ }^{127}$. Both studies suggested that the tetrameric helical form of $a$-syn is resistant to aggregation and fibril formation.

The above findings have not been verified independently. Indeed, studies from our own laboratories and three other independent groups showed that $\alpha$-syn produced in mammalian cell lines or red blood cells or isolated from the brain tissue of mice, rats, humans or $a$-syn transgenic animals exhibited identical mobility in native and denaturing gels to the unfolded monomeric $\alpha$-syn produced in $\mathrm{E}_{\text {. coli }}{ }^{46}$. NMR data of $\alpha$-syn in intact cells also ruled out the presence of stable or highly populated $\alpha$-syn oligomers and confirmed the intrinsically disordered nature of the protein in $E$. coli regardless of its purification method ${ }^{128}$. N-terminal acetylation, which was observed in native $\alpha$-syn isolated from cell lines and brain tissues, did not result in significant changes in the protein's structure, oligomeric state, membrane-binding properties or subcellular localization. These findings are in agreement with most studies on the oligomeric state of native $\alpha$-syn, which have consistently shown that $\alpha$-syn behaves as an unfolded monomer ${ }^{9,45,46}$. The migration of $\alpha$-syn with an apparent molecular weight slightly above $66 \mathrm{kDa}$ in native gels and SEC is probably the result of its tendency to adopt extended conformations, and not because it exists in an oligomeric form (for example, as a tetramer), as the addition of denaturants or boiling of $\alpha$-syn samples from various sources did not change $\alpha$-syn migration ${ }^{128}$. Although Bartels et al. ${ }^{126}$ reported that chemical crosslinking of native $\alpha$-syn primarily stabilized $\alpha$-syn tetramers, studies by several groups, including the work by Wang et al. ${ }^{127}$, showed that chemical or photochemical crosslinking of $\alpha$-syn in mammalian cells or purified $\alpha$-syn from E. coli results in the formation of a ladder of $\alpha$-syn species ranging from monomers to hexamers, with dimers being the major species ${ }^{129}$, consistent with the pattern expected for nonspecific crosslinking. Interestingly, SDS-resistant dimers seem to be the most commonly detected form of $\alpha$-syn oligomers in denaturing gels under conditions of oxidative stress ${ }^{49,130}$ or in the presence of specific metals and small molecules, such as polyphenols ${ }^{122}$. These dimers are stable in the presence of dissociative conditions such as reducing agents, chemical denaturants and boiling, suggesting that they are covalently crosslinked ${ }^{89,122}$.

The development of novel tools or methodologies that allow direct detection and monitoring of changes in $\alpha$-syn structure and oligomeric states in living cells and/or in vivo is required for assessing changes in the distribution of $\alpha$-syn conformations and oligomeric states in vivo and the role of these changes in regulating $\alpha$-syn normal function and toxicity. This knowledge is essential for the successful design of novel strategies for the diagnosis and treatment of Parkinson's disease and related synucleinopathies.

It is important to stress that in almost all of the in vivo studies described in the literature, the detection of oligomeric forms of a-syn was solely based on indirect evidence and the use of native and/or denaturing gel electrophoresis techniques ${ }^{46}$. Thus, it remains unknown to what extent the oligomers formed in vitro share similar characteristics and size to those formed in vivo or isolated from human brains or brains of transgenic animal models of synucleinopathies. Future studies would greatly benefit from tools that allow direct monitoring of protein oligomerization in living cells.

Toxicity of $\alpha$-synuclein oligomers and fibrils. Given the diversity and heterogeneity of the oligomers that form under different conditions and induce $\alpha$-syn aggregation and toxicity, it is likely that various $\alpha$-syn oligomeric species have a role in mediating $\alpha$-syn toxicity in neurons and, potentially, in glial cells.

Conversion of a-syn to a toxic oligomeric form (or forms) might be influenced by interactions with lipids or small molecules and post-translational modifications, including phosphorylation ${ }^{87}$ of $\alpha$-syn at $\$ 129$ and S87 (REF. 88), oxidative stress ${ }^{49,89}$ and truncation ${ }^{11}$. Under in vitro conditions, increasing protein concentrations, long incubations at $37^{\circ} \mathrm{C}$, addition of specific metal ions $\left(\mathrm{Fe}^{2+}, \mathrm{Cu}^{2+} \text { and } \mathrm{Zn}^{2+}\right)^{49,90}$, nitration ${ }^{89}$ or application of various ligands, such as dopamine $e^{91}$, can induce $\alpha$-syn self-assembly (FIG. 3a) and the formation of variably sized soluble aggregates that are rich in $\beta$-sheets. These range in stability and morphology, and some go on to form amyloid fibrils (FIC. 4).

Data collected in vitro and in vivo support the hypothesis that prefibrillar oligomers may represent the toxic species of $\alpha-\operatorname{syn}^{84,92}$. In vitro studies showed that annular protofibrils alter membrane permeability, resulting in an increased influx of calcium from the extracellular to intracellular space that leads to cell death ${ }^{86}$. $\alpha$-syn oligomers might also cause toxicity by damaging mitochondria ${ }^{93}$, triggering lysosomal leakage ${ }^{94}$ or disrupting microtubules ${ }^{95}$. Moreover, a recent study showed that a-syn oligomers interfere with the axonal transport of synaptic proteins such as synapsin 1, resulting in dysfunctional synapses and eventual neurodegeneration $^{25}$. It is likely that $\alpha$-syn toxicity occurs via different mechanisms and involves different intermediates on the pathway to fibril formation. However, recent evidence suggests that the process involving the conversion of oligomers to fibrils itself contributes to $a$-syn toxicity and the progression of neurodegeneration. Mutations that promote fibrillization (such as $\mathrm{S} 129 \mathrm{~A}^{96,97}$ ) also enhance $\alpha$-syn-induced toxicity and behavioural deficits in genetic rat models of PD, whereas mutations that 
- SCNA mutations

- Oxidized dopamine

- Oxidative stress

- Post-translational modifications

- Toxins

b

- Anti-aggregation approaches

- Antioxidants

- Post-translational modifications

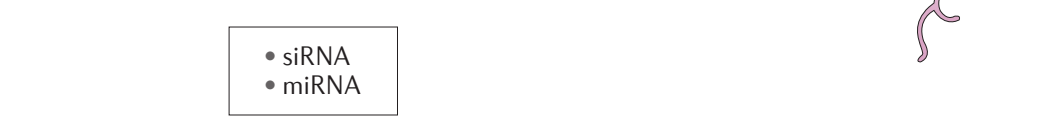

- Autophagy dysfunction

- Proteosome failure

- Dysfunction of neurosin or MMP9

- Dysfunction of heat shock proteins

$\alpha$-syn accumulation

$\psi$

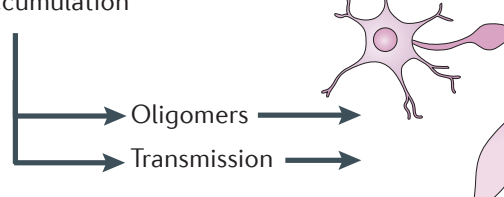

Toxicity

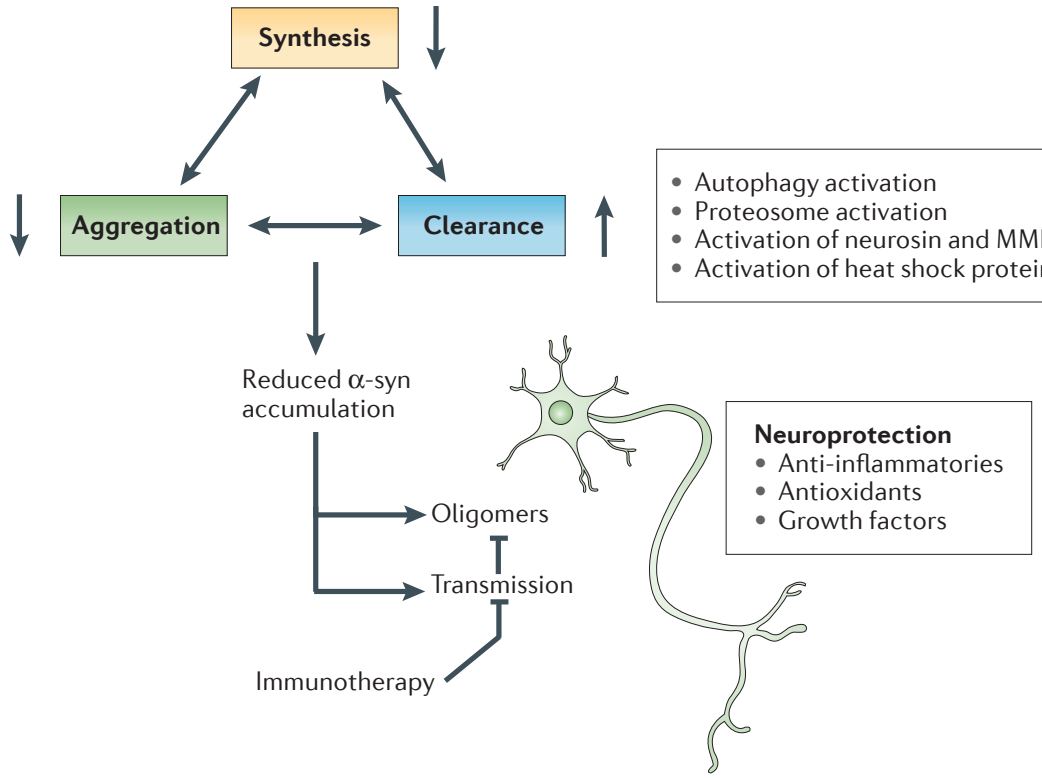

Figure 3 | Cellular events controlling intracellular $\alpha$-synuclein levels and possible therapeutic strategies to combat $\alpha$-synuclein accumulation and transmission. Intracellular $\alpha$-synuclein $(\alpha-s y n)$ levels are tightly regulated by the balance between the rates of $\alpha$-syn synthesis, clearance and aggregation. a | Abnormalities affecting $\alpha$-syn synthesis, including SNCA multiplication and polymorphisms (such as Rep1), may increase intracellular $\alpha$-syn levels and induce its accumulation. Accumulation may also be caused by a failure to degrade $\alpha$-syn. Clearance deficits might arise from failure of the ubiquitin-proteasome system, chaperone-mediated autophagy dysfunction (induced by Parkinson's disease-linked mutations) or dysfunction of proteases (neurosin or matrix metalloproteinase 9 (MMP9)). Finally, certain SNCA mutations, post-translational modifications, oxidative stress, toxins and interaction with oxidized dopamine increase the propensity of $\mathbf{a}$-syn to aggregate and accumulate. $\mathbf{b} \mid$ Strategies to reduce $\alpha$-syn accumulation include decreasing $\alpha$-syn synthesis through use of small interfering RNA (siRNA) or microRNA (miRNA). Accumulation may also be decreased by activating mechanisms or proteins involved in clearance, such as autophagy, the proteasome, neurosin, MMP9 and heat shock proteins. Additionally, aggregation of $\alpha$-syn can be decreased using anti-aggregating, antioxidant or post-translational modification approaches, and immunotherapy may be used to block transmission and oligomer formation. Finally, various $\alpha$-syn-independent neuroprotective strategies may also be used to protect neurons from $\alpha$-syn-mediated toxicity. 


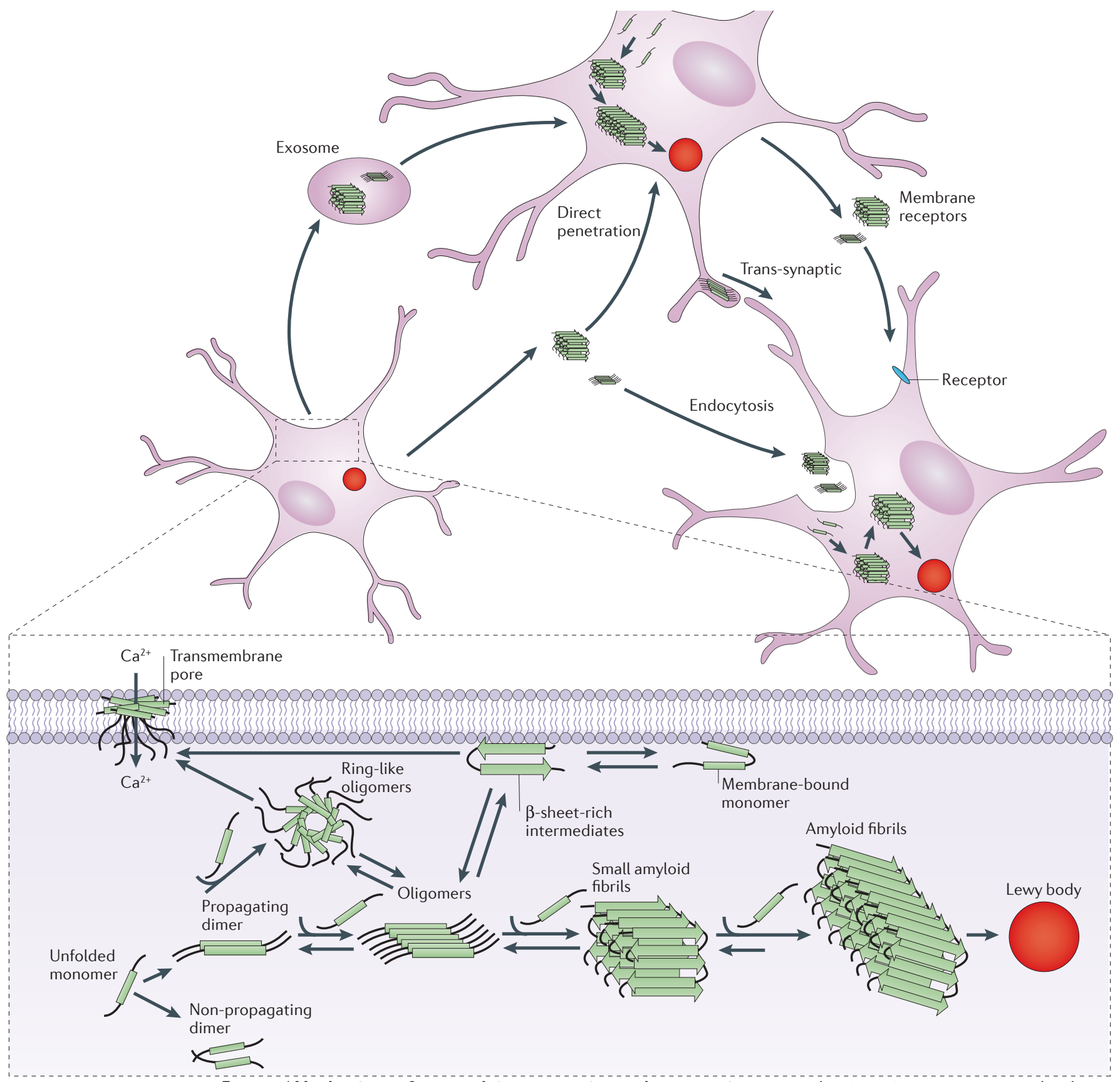

Figure $4 \mid$ Mechanisms of $\alpha$-synuclein aggregation and propagation. $\alpha$-synuclein ( $\alpha$-syn) aggregation can take place either in the cytoplasm or in association with the cellular membrane. In the cytosol, unfolded monomers interact to form initially unstable dimers, which grow slowly to generate oligomers of varying morphologies - including transient spherical and ring-like oligomers - that eventually convert to fibrils. The $\alpha$-syn oligomers are in equilibrium with monomers and convert to fibrils by monomer addition via a nucleated polymerization mechanism. The accumulation of these amyloid fibrils leads to the formation of intracellular inclusions called Lewy bodies. Membrane-bound monomeric $\alpha$-syn adopts a predominantly $\alpha$-helical confirmation, but at high concentrations the protein undergoes a conformational change either before or coincident with its oligomerization to form membrane-bound $\beta$-sheet-rich structures that self-associate to form oligomers, including trans-membrane amyloid pores (the formation of which may involve several intermediates $)^{131}$ and fibrils. Note that the ring-like cytosolic oligomers may also associate with the membrane and form trans-membrane pores. During a-syn fibrillogenesis and aggregation, the intermediate species (oligomers and amyloid fibrils) are highly toxic, affecting mitochondrial function, endoplasmic reticulum-Golgi trafficking, protein degradation and/or synaptic transmission, and these intracellular effects are thought to induce neurodegeneration. The transmembrane pores disrupt membrane integrity as well as intracellular calcium homeostasis and signalling, and may also contribute to neuronal toxicity. Interestingly, $\alpha$-syn oligomers and fibrils, as well as the monomers, can be transferred between cells and induce disease spreading to other brain regions. Spreading mechanisms are multiple and can occur via endocytosis, direct penetration, trans-synaptic transmission or membrane receptors. Once inside the host cells, $\alpha$-syn aggregates can nucleate aggregation and propagate via the mechanisms described above. 


\section{Box 2 | Key terminology in the field of prion-like diseases}

The term 'transmission' means the conveyance of non-prion proteins, whereas the terms 'propagation', 'spreading', 'transfer' and 'dissemination' are used interchangeably to indicate the dispersal of protein over a larger area, as well as from cell to cell. 'Seeding' is synonymous with the addition of preformed aggregates to a solution of monomers. This process can eliminate the lag phase of aggregate growth that is associated with the formation of soluble assembly-competent oligomers (known as the 'nuclei') and can accelerate fibril formation. Seeding is the theoretical basis for prion infectivity, or the conveyance of prion proteins from animal to animal.

block $\alpha$-syn oligomerization and fibrillogenesis (such as S87E) induce significantly less $\alpha$-syn aggregation, fibre pathology and dopaminergic loss in rat midbrains ${ }^{88}$. Artificial mutant variants of $\alpha$-syn (for example, E57K $\alpha$-syn) that enhance the formation of $\alpha$-syn oligomers but not fibrils were shown to be highly toxic to dopaminergic neurons in different animal models of synucleinopathies ${ }^{98}$. In addition, Taschenberger and colleagues showed that mutations that enhance $\alpha$-syn oligomerization (that is, A56P and the triple mutant A30P/A56P/ A76P) exhibit high toxicity, but sustained progressive loss of dopaminergic neurons was strongly dependent on the ability of the $\alpha$-syn variant to form fibrils in vivo ${ }^{12}$. These results are consistent with recent findings in the amyloid- $\beta$ field ${ }^{99,100}$ and demonstrate that the process of fibril formation, rather than the fibrils themselves, has an important role in $\alpha$-syn toxicity and progressive neurodegeneration in PD and related disorders. Thus, it is possible that toxicity might be related to the process of aggregation rather than just to the final outcome (that is, oligomers or fibrils).

Although most of the studies mentioned here suggest that $\alpha$-syn oligomerization and/or fibrillogenesis has a central role in $\alpha$-syn toxicity, it is important to stress that most of the evidence demonstrating comparatively reduced toxicity for monomeric $\alpha$-syn is based on the use of recombinant proteins in extracellular toxicity assays or on the correlation between high levels of a-syn oligomers (as determined by SDS-PAGE) and the progression of neurodegeneration in transgenic animals and other experimental models.

Of note, none of the available data excludes the two other possibilities, the first of which is that $\alpha$-syn oligomerization within specific cellular compartments may alter the distribution of functional forms of monomeric a-syn or result in monomer sequestration into nonfunctional oligomeric forms, thus resulting in partial loss of $\alpha$-syn function ${ }^{101}$. The second possibility is that the native or misfolded forms of the monomeric protein may also contribute to $\alpha$-syn toxicity and PD pathogenesis via aggregation-independent mechanisms, including aberrant interactions with membranes, proteins and small molecules, retention in specific cellular compartments, and disruption of specific cellular processes. Unlike stable oligomeric forms of $\alpha$-syn, which can be easily distinguished from monomers and fibrils, the existing experimental tools do not allow the detection and characterization of different $\alpha$-syn monomeric conformers and thus preclude studies aimed at investigating the role of the $\alpha$-syn monomer in health and disease.
Propagation and transmission of $\alpha$-synuclein in the pathogenesis of PD. Under physiological conditions, a-syn has been traditionally considered to be an exclusively intracellular synaptic protein that associates with vesicles ${ }^{15}$. However, recent evidence suggests that under pathological circumstances, toxic a-syn oligomers could be eliminated from neurons via unusual secretory mechanisms ${ }^{102-104}$ (FIG. 4). Failure of the intracellular clearance pathways, such as autophagy, might contribute to the pathological release of $\alpha-\operatorname{syn}^{105}$. Pathways leading to the release of toxic $\alpha$-syn oligomers include exocytosis in clear vesicles $^{105}$, exosomal release ${ }^{103,106}$ and penetration ${ }^{79,107}$ from the donor cell membrane (FIG. 4). Interestingly, these extracellular $\alpha$-syn aggregates can then transfer from neuron to neuron or from neuron to glial cell ${ }^{105}$, where they can nucleate further intracellular aggregation and/or trigger neuro-inflammation to exacerbate the neurodegenerative process ${ }^{69,108}$. Supporting the potential relevance of this process in the pathogenesis of a-synucleinopathies, previous studies have shown accumulation of $\alpha$-syn in fetal grafted neurons in patients with $\mathrm{PD}^{109,110}$, as well as in grafted neuronal precursor cells in the hippocampus ${ }^{69}$ and basal ganglia ${ }^{111}$ in mouse models. Interestingly, $\alpha$-syn has also been shown to ectopically accumulate in oligodendroglial cells in multiple system atrophy (another synucleinopathy) $)^{112}$ and in astroglial cells in $\mathrm{PD}^{113,114}$. Moreover, the ascending distribution of the Lewy body pathology in LBD, as described by Braak ${ }^{113}$, has been interpreted to support the dissemination of a-syn from subcortical to cortical brain regions. However, further in vivo experimental verification of this is needed. A definition for the terms of propagation, dissemination and infectivity is provided in BOX 2.

The mechanisms through which extracellular $\alpha$-syn oligomers transfer to other cells include endocytosis ${ }^{115}$, direct penetration ${ }^{116}$, trans-synaptic dissemination ${ }^{103}$ and membrane-receptor-mediated access ${ }^{105}$. Once inside the acceptor cell, a-syn oligomers could act as a focal point for further intracellular aggregation or the protein could be targeted for degradation. Although the exact process of intracellular oligomer and fibril propagation remains unknown, evidence from in vitro biophysical studies has consistently shown that fibrillization of $\alpha$-syn follows a nucleated polymerization mechanism ${ }^{92}$. This mechanism is characterized by a nucleation phase that initially involves the formation of assembly-competent oligomers (nuclei), which is followed by cooperative oligomer growth and fibril formation by monomer addition ${ }^{117}$ (FIG. 4). This process can be seeded (initiated) and accelerated by the addition of preformed fibrils (the seed) and is thought to serve as the underlying mechanism for the spreading of a-syn pathology in the brain. This phenomenon has been observed in a cell-based assay in which the introduction of recombinant $\alpha$-syn fibrils results in seeding, the recruitment of endogenous $\alpha$-syn and the formation of Lewy body-like inclusions ${ }^{44}$. A recent in vivo study has shown that inoculation of $\alpha$-syn transgenic mice with homogenates containing $a$-syn protofibrils and fibrils results in considerable enhancement of the 
a-syn pathology and propagation ${ }^{118}$. These observations have led to the provocative hypothesis that extracellular a-syn seeds might behave in a prion-like fashion. Further experimental evidence is needed to confirm this hypothesis.

\section{Perspectives on therapeutic targets}

Given the potential toxicity of various $\alpha$-syn aggregates, therapeutic approaches for synucleinopathies might involve reducing the levels or accumulation of intracellular and extracellular $\alpha$-syn. One way to reduce the accumulation of intracellular $\alpha$-syn may be to reduce the expression of this protein by silencing SNCA with microRNA or by repressing the SNCA promoter (FIG. 3b). Another approach could involve clearing $\alpha$-syn by activating autophagy or the proteasome, by increasing proteolytic breakdown of $\alpha$-syn with cathepsin $D$, neurosin or MMP9, or by promoting the binding of $\alpha$-syn to chaperone-like molecules such as $\beta$-syn and HSPs (FIG. 3b). A third approach would be to reduce the post-translational modifications, such as oxidation, nitration, phosphorylation and C-terminal cleavage (FIG. 3b). Two other possibilities may be to reduce aggregation or stabilize the native state of $a$-syn (FIG. 3b).

Resolving the question of whether $a$-syn exists as a monomer or as an oligomer under physiological and pathophysiological conditions is important not only in defining the function of this molecule but also in terms of developing therapeutic approaches for synucleinopathies. For example, if native $\alpha$-syn exists as a multimer, which has not yet been proven, then one therapeutic strategy for PD and DLB could involve preventing this complex from breaking apart. However, if toxic a-syn oligomers are derived from single conformers, viable therapeutic approaches might include the stabilization of monomers, the stabilization of non-propagating $\alpha$-syn dimers, the inhibition of $\alpha$-syn oligomerization and the prevention of interactions between monomers and protofibrils that result in fibril growth. As in vitro studies of multiple amyloidogenic proteins ${ }^{119}$ have shown that fibril growth and disassembly occur via monomer addition to protofibrils and disassociation, respectively, $a$-syn toxicity would be dependent not only on the levels of oligomers but also on the concentration of the monomers. The main issue relating to developing small molecules to stabilize monomeric $\alpha$-syn or prevent the formation of toxic forms of $\alpha$-syn is that the monomer lacks a well-defined structure or hydrophobic pockets. Additionally, the identity and three-dimensional structure of toxic oligomeric species and their mode of action remain the subject of active investigation and debate.

If oligomeric $\alpha$-syn species are the primary cause of toxicity in synucleinopathies, then inhibition of $\alpha$-syn oligomerization or enhancement of $\alpha$-syn fibrillization should attenuate $\alpha$-syn toxicity and prevent neurodegeneration. Conversely, small molecules and/or mutations that stabilize toxic $\alpha$-syn oligomers should enhance neurodegeneration. Interestingly, the large majority of molecules that inhibit $\alpha$-syn fibrillization exert their effects by stabilizing high-molecular-weight oligomeric intermediates on the amyloid pathway ${ }^{120}$ and protect, rather than enhance, $\alpha$-syn toxicity ${ }^{121}$. This protective effect might be related to the antioxidant and anti-inflammatory properties of some of these compounds, such as polyphenols and curcuminoids ${ }^{122}$. Alternatively, it is possible that the binding of these molecules to oligomeric species of $\alpha$-syn blocks interactions between $\alpha$-syn and key mediators of $\alpha$-syn-associated toxicity. Interestingly, this seems to be the case for most amyloid- $\beta$ inhibitors as well ${ }^{123}$ : the majority of the compounds shown to protect against amyloid- $\beta$ toxicity do not stabilize monomeric amyloid- $\beta$ and promote the accumulation of oligomers and/or non-fibrillar aggregates of various sizes and morphologies. It is possible that these molecules induce remodelling of the toxic oligomers and/or promote the formation of non-toxic aggregate or pathways. A recent study by Ayrolles-Torro et al. ${ }^{124}$ showed that small molecule inhibitors that stabilize oligomeric forms of the prion protein attenuate prion infectivity in vivo, again suggesting a direct link between the processes of oligomer growth, fibrillization and prion infectivity.

The levels of toxic extracellular $a$-syn aggregates may be reduced by targeting them with specific antibodies (passive and active immunotherapy), by increasing clearance, by blocking putative receptors for extracellular $\alpha$-syn in acceptor cells, by reducing $\alpha$-syn endocytosis and exocytosis or by targeting exosomes. Moreover, given the pro-inflammatory effects of $\alpha$-syn, reducing microglial or astroglial activation with nonsteroidal anti-inflammatory drugs may also be a fruitful area of research ${ }^{125}$. Currently, the most viable therapeutic strategies for PD, DLB and related disorders may be to use the considerable biophysical and structural data available for the single conformation of a-syn to target a-syn monomers and decrease their synthesis, increase their clearance, block their interactions with oligomers or promote their stabilization. Ultimately, developing a successful therapy for synucleinopathies will require multidisciplinary research combined with multimodal therapeutics.

\section{Conclusions}

Since the discovery of $\alpha$-syn in the mammalian brain, research has focused on better understanding the contributions of this natively unfolded protein to vesicular synaptic function under normal conditions. The discovery of disease-linked mutations and multiplications in SNCA that cause familial PD and accelerate $\alpha$-syn oligomerization in vitro has resulted in greater emphasis on elucidating the role of $\alpha$-syn oligomers and fibrils as well as prion-like $\alpha$-syn propagation in the pathogenesis of LBDs. Therapeutic interventions directed at reducing a-syn synthesis, toxicity and aggregation or at increasing a-syn clearance are currently being investigated in preclinical models and hold promise for developing future treatments for $\alpha$-synucleinopathies. We believe that more emphasis on elucidating the molecular and structural bases of the suspected physiological functions of $\alpha$-syn is needed. This may help us to further understand the functions of this protein and provide novel molecular targets for therapeutic intervention in a-syn-linked diseases. 
1. McKeith, I. G. et al. Consensus guidelines for the clinical and pathologic diagnosis of dementia with Lewy bodies (DLB): report of the consortium on DLB international workshop. Neurology 47, 1113-1124 (1996).

2. Braak, H. \& Braak, E. Pathoanatomy of Parkinson's disease. J. Neurol. 247, II3-II 10 (2000). A detailed description of the pathoanatomy that occurs in PD.

3. Vekrellis, K., Xilouri, M., Emmanouilidou, E., Rideout, H. J. \& Stefanis, L. Pathological roles of a-synuclein in neurological disorders. Lancet Neurol. 10, 1015-1025 (2011).

4. Chartier-Harlin, M. C. et al. $\alpha$-synuclein locus duplication as a cause of familial Parkinson's disease. Lancet 364, 1167-1169 (2004).

5. Kruger, R. et al. Ala30Pro mutation in the gene encoding $\alpha$-synuclein in Parkinson's disease. Nature Genet. 18, 106-108 (1998)

6. Polymeropoulos, M. H. et al. Mutation in the a-synuclein gene identified in families with Parkinson's disease. Science 276, 2045-2047 (1997)

7. Zarranz, J. J. et al. The new mutation, E46K, of a-synuclein causes Parkinson and Lewy body dementia. Ann. Neurol. 55, 164-173 (2004).

8. Simon-Sanchez, J. et al. Genome-wide association study reveals genetic risk underlying Parkinson's disease. Nature Genet. 41, 1308-1312 (2009).

9. Conway, K. A., Harper, J. D. \& Lansbury, P. T. Accelerated in vitro fibril formation by a mutant $\alpha$-synuclein linked to early-onset Parkinson disease. Nature Med. 4, 1318-1320 (1998).

10. Tsigelny, I. F. et al. Mechanisms of hybrid oligomer formation in the pathogenesis of combined Alzheimer's and Parkinson's diseases. PLOS ONE 3 , e3135 (2008).

11. Oueslati, A., Fournier, M. \& Lashuel, H. A. Role of post-translational modifications in modulating the structure, function and toxicity of $\alpha$-synuclein: implications for Parkinson's disease pathogenesis and therapies. Prog. Brain Res. 183, 115-145 (2010).

12. Taschenberger, G. et al. Aggregation of $\alpha$-synuclein promotes progressive in vivo neurotoxicity in adult rat dopaminergic neurons. Acta Neuropathol. 123, 671-683 (2011).

13. Galvin, J. E., Lee, V. M. \& Trojanowski, J. O. Synucleinopathies: clinical and pathological implications. Arch. Neurol. 58, 186-190 (2001).

14. Wang, S. et al. a-Synuclein disrupts stress signaling by inhibiting polo-like kinase Cdc5/PIk2. Proc. Natl Acad. Sci. USA 109, 16119-16124 (2012).

15. Iwai, A. et al. The precursor protein of non- $A \beta$ component of Alzheimer's disease amyloid is a presynaptic protein of the central nervous system. Neuron 14, 467-475 (1995).

This study identified NAC as a presynaptic protein

16. Jakes, R., Spillantini, M. G. \& Goedert, M Identification of two distinct synucleins from human brain. FEBS Lett. 345, 27-32 (1994).

17. Withers, G. S., George, J. M., Banker, G. A. \& Clayton, D. F. Delayed localization of synelfin (synuclein, NACP) to presynaptic terminals in cultured rat hippocampal neurons. Brain Res. Dev. Brain Res. 99, 87-94 (1997)

18. Kahle, P. J. et al. Subcellular localization of wild-type and Parkinson's disease-associated mutant $\alpha$-synuclein in human and transgenic mouse brain. J. Neurosci. 20, 6365-6373 (2000)

19. Lee, S. J., Jeon, H. \& Kandror, K. V. a-synuclein is localized in a subpopulation of rat brain synaptic vesicles. Acta Neurobiol. Exp. 68, 509-515 (2008).

20. Zhang, L. et al. Semi-quantitative analysis of $\alpha$-synuclein in subcellular pools of rat brain neurons: an immunogold electron microscopic study using a C-terminal specific monoclonal antibody. Brain Res. 1244, 40-52 (2008)

21. Cabin, D. E. et al. Synaptic vesicle depletion correlates with attenuated synaptic responses to prolonged repetitive stimulation in mice lacking $\alpha$-synuclein. J. Neurosci. 22, 8797-8807 (2002).

22. Abeliovich, A. et al. Mice lacking $\alpha$-synuclein display functional deficits in the nigrostriatal dopamine system. Neuron. 25, 239-252 (2000).

23. Murphy, D. D., Rueter, S. M., Trojanowski, J. Q. \& Lee, V. M. Synucleins are developmentally expressed and $\alpha$-synuclein regulates the size of the presynaptic vesicular pool in primary hippocampal neurons. J. Neurosci. 20, 3214-3220 (2000)

24. Yavich, L., Tanila, H., Vepsalainen, S. \& Jakala, P. Role of $\alpha$-synuclein in presynaptic dopamine recruitment. J. Neurosci. 24, 11165-11170 (2004).
25. Scott, D. A. et al. A pathologic cascade leading to synaptic dysfunction in $\alpha$-synuclein-induced neurodegeneration. J. Neurosci. 30, 8083-8095 (2010).

26. Nemani, V. M. et al. Increased expression of $\alpha$-synuclein reduces neurotransmitter release by inhibiting synaptic vesicle reclustering after endocytosis. Neuron 65, 66-79 (2010). This study found that $\alpha$-syn overexpression inhibited neurotransmitter release by reducing the size of the synaptic vesicle recycling pool.

27. Gaugler, M. N. et al. Nigrostriatal overabundance of $\alpha$-synuclein leads to decreased vesicle density and deficits in dopamine release that correlate with reduced motor activity. Acta Neuropathol. 123 653-669 (2012).

28. Lundblad, M., Decressac, M., Mattsson, B. \& Bjorklund, A. Impaired neurotransmission caused by overexpression of $\alpha$-synuclein in nigral dopamine neurons. Proc. Natl Acad. Sci. USA 109, 3213-3219 (2012).

29. Larsen, K. E. et al. $\alpha$-synuclein overexpression in PC12 and chromaffin cells impairs catecholamine release by interfering with a late step in exocytosis. J. Neurosci. 26, 11915-11922 (2006)

30. Scott, D. \& Roy, S. a-synuclein inhibits intersynaptic vesicle mobility and maintains recycling-pool homeostasis. J. Neurosci. 32, 10129-10135 (2012).

31. Payton, J. E., Perrin, R. J., Woods, W. S. \& George, J. M. Structural determinants of PLD2 inhibition by a-synuclein. J. Mol. Biol. 337 , 1001-1009 (2004)

32. Dalfo, E. \& Ferrer, I. $\alpha$-synuclein binding to rab3a in multiple system atrophy. Neurosci. Lett. $\mathbf{3 8 0}$, 170-175 (2005)

33. Burre, J. et al. $\alpha$-synuclein promotes SNARE-complex assembly in vivo and in vitro. Science 329 1663-1667 (2010)

This paper identifies $\alpha$-synuclein as a non-classical chaperone that binds and promotes

SNARE-complex assembly.

34. Chandra, S. et al. Double-knockout mice for $\alpha$ - and $\beta$-synucleins: effect on synaptic functions. Proc. Natl Acad. Sci. USA 101, 14966-14971 (2004).

35. Chandra, S., Gallardo, G., Fernandez-Chacon, R. Schluter, O. M. \& Sudhof, T. C. $\alpha$-synuclein cooperates with CSPa in preventing neurodegeneration. Cell 123, 383-396 (2005)

36. Ueda, K. et al. Molecular cloning of cDNA encoding an unrecognized component of amyloid in Alzheimer disease. Proc. Natl Acad. Sci. USA 90, 11282-11286 (1993).

This is the first report of the NAC being a 140-amino-acid protein.

37. Ulmer, T. S., Bax, A., Cole, N. B. \& Nussbaum, R. L. Structure and dynamics of micelle-bound human a-synuclein. J. Biol. Chem. 280, 9595-9603 (2005).

38. Eliezer, D., Kutluay, E., Bussell, R. Jr \& Browne, G. Conformational properties of $\alpha$-synuclein in its free and lipid-associated states. J. Mol. Biol. 307, 1061-1073 (2001).

39. Masliah, E., Iwai, A., Mallory, M., Ueda, K. \& Saitoh, T Altered presynaptic protein NACP is associated with plaque formation and neurodegeneration in Alzheimer's disease. Am. J. Pathol. 148, 201-210 (1996)

40. Spillantini, M. G. et al. $\alpha$-synuclein in Lewy bodies. Nature 388, 839-840 (1997).

41. Hashimoto, M., Takenouchi, T., Mallory, M., Masliah, $\mathrm{E} \&$ Takeda, A. The role of NAC in amyloidogenesis in Alzheimer's disease. Am. J. Pathol. 156, 734-736 (2000)

42. El-Agnaf, O. M., Jakes, R., Curran, M. D. \& Wallace, A. Effects of the mutations Ala30 to Pro and Ala53 to Thr on the physical and morphological properties of a-synuclein protein implicated in Parkinson's disease. FEBS Lett. 440, 67-70 (1998).

43. Giasson, B. I., Murray, I. V., Trojanowski, J. O. \& Lee, V. M. A hydrophobic stretch of 12 amino acid residues in the middle of $\alpha$-synuclein is essential for filament assembly. J. Biol. Chem. 276, 2380-2386 (2001).

This study showed that the middle hydrophobic domain of $\alpha$-syn is necessary and sufficient for fibrillization.

44. Luk, K. C. et al. Exogenous $\alpha$-synuclein fibrils seed the formation of Lewy body-like intracellular inclusions in cultured cells. Proc. Natl Acad. Sci. USA 106, 20051-20056 (2009)

These authors showed that $\alpha$-syn seeds can recruit endogenous soluble $\alpha$-syn protein to form pathological species.
45. Weinreb, P. H., Zhen, W., Poon, A. W., Conway, K. A. \& Lansbury, P. T. Jr. NACP, a protein implicated in Alzheimer's disease and learning, is natively unfolded. Biochemistry 35, 13709-13715 (1996).

46. Fauvet, B. et al. $\alpha$-synuclein in the central nervous system and from erythrocytes, mammalian cells and E. coli exists predominantly as a disordered monomer. J. Biol. Chem. 287, 15345-15364 (2012). This study reassessed the oligomeric state of $\alpha$-syn and demonstrated that native $\alpha$-syn exists predominantly as an unfolded monomer and not a tetramer.

47. Ramakrishnan, M., Jensen, P. H. \& Marsh, D. Association of $\alpha$-synuclein and mutants with lipid membranes: spin-label ESR and polarized IR. Biochemistry 45, 3386-3395 (2006)

48. Ullman, O., Fisher, C. K. \& Stultz, C. M. Explaining the structural plasticity of $\alpha$-synuclein. J. Am. Chem. Soc. 133, 19536-19546 (2011)

49. Hashimoto, M. et al. Oxidative stress induces amyloidlike aggregate formation of NACP/ $\alpha$-synuclein in vitro. Neuroreport 10, 717-721 (1999).

50. Andringa, G. et al. Tissue transglutaminase catalyzes the formation of $\alpha$-synuclein crosslinks in Parkinson's disease. FASEB J. 18, 932-934 (2004).

51. Paleologou, K. E. et al. Phosphorylation at S87 is enhanced in synucleinopathies, inhibits $\alpha$-synuclein oligomerization, and influences synuclein-membrane interactions. J. Neurosci. 30, 3184-3198 (2010)

52. Li, W. et al. Aggregation promoting C-terminal truncation of $\alpha$-synuclein is a normal cellular process and is enhanced by the familial Parkinson's diseaselinked mutations. Proc. Natl Acad. Sci. USA 102, 2162-2167 (2005)

53. Dufty, B. M. et al. Calpain-cleavage of $\alpha$-synuclein connecting proteolytic processing to disease-linked aggregation. Am. J. Pathol. 170, 1725-1738 (2007).

54. Perrin, R. J., Woods, W. S., Clayton, D. F. \& George, J. M. Exposure to long chain polyunsaturated fatty acids triggers rapid multimerization of synucleins. J. Biol. Chem. 276, 41958-41962 (2001).

55. Sharon, R. et al. The formation of highly soluble oligomers of $\alpha$-synuclein is regulated by fatty acids and enhanced in Parkinson's disease. Neuron 37 583-595 (2003)

56. Karube, $\mathrm{H}$. et al. $\mathrm{N}$-terminal region of $\alpha$-synuclein is essential for the fatty acid-induced oligomerization of the molecules. FEBS Lett. 582, 3693-3700 (2008).

57. Takeda, A. et al. Abnormal distribution of the non-A $\beta$ component of Alzheimer's disease amyloid precursor $\alpha$-synuclein in Lewy body disease as revealed by proteinase $\mathrm{K}$ and formic acid pretreatment. $\mathrm{Lab}$. Invest. 78, 1169-1177 (1998)

58. Suh, Y. H. \& Checler, F. Amyloid precursor protein, presenilins, and $\alpha$-synuclein: molecular pathogenesis and pharmacological applications in Alzheimer's disease. Pharmacol. Rev. 54, 469-525 (2002)

59. Iwai, A. et al. The synaptic protein NACP is abnormally expressed during the progression of Alzheimer's disease. Brain Res. 720, 230-234 (1996).

60. Kragh, C. L., Ubhi, K., Wyss-Corey, T. \& Masliah, E. Autophagy in dementias. Brain Pathol. 22, 99-109 (2012).

61. Seidel, K. et al. First appraisal of brain pathology owing to A30P mutant $\alpha$-synuclein. Ann. Neurol. 67 684-689 (2010)

62. Maraganore, D. M. et al. Collaborative analysis of $\alpha$-synuclein gene promoter variability and Parkinson disease. JAMA 296, 661-670 (2006)

63. Iwata, A. et al. a-synuclein degradation by serine protease neurosin: implication for pathogenesis of synucleinopathies. Hum. Mol. Genet. 12, 2625-2635 (2003).

64. Klucken, J., Shin, Y., Masliah, E., Hyman, B. T. \& McLean, P. J. Hsp70 reduces $\alpha$-synuclein aggregation and toxicity. J. Biol. Chem. 279, 25497-25502 (2004).

65. McNaught, K. S. et al. Impairment of the ubiquitinproteasome system causes dopaminergic cell death and inclusion body formation in ventral mesencephalic cultures. J. Neurochem 81, 301-306 (2002).

66. McNaught, K. S. et al. Proteasome inhibition causes nigral degeneration with inclusion bodies in rats. Neuroreport 13, 1437-1441 (2002)

67. Webb, J. L., Ravikumar, B., Atkins, J., Skepper, J. N. \& Rubinsztein, D. C. $\alpha$-Synuclein is degraded by both autophagy and the proteasome. J. Biol. Chem. 278 25009-25013 (2003).

68. Cuervo, A. M., Stefanis, L., Fredenburg, R. Lansbury, P. T. \& Sulzer, D. Impaired degradation of mutant $\alpha$-synuclein by chaperone-mediated autophagy. Science 305, 1292-1295 (2004). 
This paper identified lysosomes for degradation of wild-type $\alpha$-syn by the chaperone-mediated autophagy pathway.

69. Desplats, P. et al. Inclusion formation and neuronal cell death through neuron-to-neuron transmission of a-synuclein. Proc. Natl Acad. Sci. USA 106 13010-13015 (2009).

70. Spencer, B. et al. Beclin 1 gene transfer activates autophagy and ameliorates the neurodegenerative pathology in $\alpha$-synuclein models of Parkinson's and Lewy body diseases. J. Neurosci. 29, 13578-13588 (2009).

71. Crews, L. et al. Selective molecular alterations in the autophagy pathway in patients with Lewy body disease and in models of $\alpha$-synucleinopathy. PLOS ONE 5, e9313 (2010)

72. Kosaka, K. Diffuse Lewy body disease in Japan J. Neurol. 237, 197-204 (1990).

73. Dickson, D. W. et al. Diffuse Lewy body disease: light and electron microscopic immunocytochemistry of senile plaques. Acta Neuropathol. 78, 572-584 (1989).

74. Braak, H., Sastre, M. \& Del Tredici, K. Development of $\alpha$-synuclein immunoreactive astrocytes in the forebrain parallels stages of intraneuronal pathology in sporadic Parkinson's disease. Acta Neuropathol. 114, 231-241 (2007).

Paper reporting the association of $\alpha$-syn with reactive astrocytes in clinically diagnosed PD cases.

75. Lee, H. J. et al. Direct transfer of $\alpha$-synuclein from neuron to astroglia causes inflammatory responses in synucleinopathies. J. Biol. Chem. 285, 9262-9272 (2010).

76. Kahle, P. J. et al. Selective insolubility of $\alpha$-synuclein in human Lewy body diseases is recapitulated in a transgenic mouse model. Am. J. Pathol. 159 2215-2225 (2001).

77. Baba, M. et al. Aggregation of $\alpha$-synuclein in Lewy bodies of sporadic Parkinson's disease and dementia with Lewy bodies. Am. J. Pathol. 152, 879-884 (1998).

78. Lee, M. K. et al. Human $\alpha$-synuclein-harboring familial Parkinson's disease-linked Ala-53 $\rightarrow$ Thr mutation causes neurodegenerative disease with $\alpha$-synuclein aggregation in transgenic mice. Proc. Natl Acad. Sci. USA 99, 8968-8973 (2002).

79. Tsigelny, I. F. et al. Role of $\alpha$-synuclein penetration into the membrane in the mechanisms of oligomer pore formation. FEBS J. 279, 1000-1013 (2012). Computational modelling shows that $\alpha$-synuclein can form ring-like structures that penetrate the membrane.

80. Bellucci, A., Navarria, L., Zaltieri, M., Missale, C. \& Spano, P. $\alpha$-synuclein synaptic pathology and its implications in the development of novel therapeutic approaches to cure Parkinson's disease. Brain Res. 1432, 95-113 (2012).

81. Schulz-Schaeffer, W. J. The synaptic pathology of $\alpha$-synuclein aggregation in dementia with Lewy bodies, Parkinson's disease and Parkinson's disease dementia. Acta Neuropathol. 120, 131-143 (2010).

82. Garcia-Reitbock, P. et al. SNARE protein redistribution and synaptic failure in a transgenic mouse model of Parkinson's disease. Brain 133, 2032-2044 (2010).

83. Horvath, I. et al. Mechanisms of protein oligomerization: inhibitor of functional amyloids templates $\alpha$-synuclein fibrillation. J. Am. Chem. Soc 134, 3439-3444 (2012).

84. Conway, K. A. et al. Accelerated oligomerization by Parkinson's disease linked $\alpha$-synuclein mutants. Ann NY Acad. Sci. 920, 42-45 (2000).

85. Cremades, N. et al. Direct observation of the interconversion of normal and toxic forms of a-synuclein. Cell 149, 1048-1059 (2012).

86. Danzer, K. M. et al. Different species of $\alpha$-synuclein oligomers induce calcium influx and seeding. J. Neurosci. 27, 9220-9232 (2007)

87. Iwatsubo, T. Pathological biochemistry of a-synucleinopathy. Neuropathology 27, 474-478 (2007).

88. Oueslati, A., Paleologou, K. E., Schneider, B. L., Aebischer, P. \& Lashuel, H. A. Mimicking phosphorylation at serine 87 inhibits the aggregation of human $\alpha$-synuclein and protects against its toxicity in a rat model of Parkinson's disease. J. Neurosci. 32, 1536-1544 (2012).

89. Souza, J. M., Giasson, B. I., Chen, Q., Lee, V. M. \& Ischiropoulos, H. Dityrosine cross-linking promotes formation of stable $\alpha$-synuclein polymers. Implication of nitrative and oxidative stress in the pathogenesis of neurodegenerative synucleinopathies. J. Biol. Chem 275, 18344-18349 (2000)
90. Uversky, V. N., Li, J. \& Fink, A. L. Metal-triggered structural transformations, aggregation, and fibrillation of human $\alpha$-synuclein - a possible molecular link between Parkinson's disease and heavy metal exposure. J. Biol. Chem. 276, 44284-44296 (2001).

91. Conway, K. A., Rochet, J. C., Bieganski, R. M. \& Lansbury, P. T. Jr. Kinetic stabilization of the $\alpha$-synuclein protofibril by a dopamine- $\alpha$-synuclein adduct. Science 294, 1346-1349 (2001).

92. Conway, K. A. et al. Acceleration of oligomerization, not fibrillization, is a shared property of both $\alpha$-synuclein mutations linked to early-onset Parkinson's disease: implications for pathogenesis and therapy. Proc. Natl Acad. Sci. USA 97, 571-576 (2000).

93. Hsu, L. J. et al. $\alpha$-synuclein promotes mitochondrial deficit and oxidative stress. Am. J. Pathol. 157, 401-410 (2000).

94. Hashimoto, M. et al. The role of $\alpha$-synuclein assembly and metabolism in the pathogenesis of Lewy body disease. J. Mol. Neurosci. 24, 343-352 (2004).

95. Alim, M. A. et al. Demonstration of a role for $\alpha$-synuclein as a functional microtubule-associated protein. J. Alzheimers Dis. 6, 435-442 (2004).

96. da Silveira, S. A. et al. Phosphorylation does not prompt, nor prevent, the formation of $\alpha$-synuclein toxic species in a rat model of Parkinson's disease. Hum Mol. Genet. 18, 872-887 (2009).

97. Gorbatyuk, O. S. et al. The phosphorylation state of Ser-129 in human $\alpha$-synuclein determines neurodegeneration in a rat model of Parkinson disease. Proc. Natl Acad. Sci. USA 105, 763-768 (2008)

98. Winner, B. et al. In vivo demonstration that $\alpha$-synuclein oligomers are toxic. Proc. Natl Acad. Sci. USA 108 4194-4199 (2011)

99. Jan, A. et al. A $\beta 42$ neurotoxicity is mediated by ongoing nucleated polymerization process rather than by discrete $\mathrm{A} \beta 42$ species. J. Biol. Chem. 286, 8585-8596 (2011)

100. Wogulis, M. et al. Nucleation-dependent polymerization is an essential component of amyloidmediated neuronal cell death. J. Neurosci. 25 , 1071-1080 (2005)

101. Colla, E. et al. Accumulation of toxic $a$-synuclein oligomer within endoplasmic reticulum occurs in a-synucleinopathy in vivo. J. Neurosci. 32, 3301-3305 (2012)

102. Jang, A et al. Non-classical exocytosis of $\alpha$-synuclein is sensitive to folding states and promoted under stress conditions. J. Neurochem. 113, 1263-1274 (2010).

103. Danzer, K. M. et al. Heat-shock protein 70 modulates toxic extracellular $\alpha$-synuclein oligomers and rescues trans-synaptic toxicity. FASEB J. 25, 326-336 (2011).

104. Alvarez-Erviti, L. et al. Lysosomal dysfunction increases exosome-mediated $\alpha$-synuclein release and transmission. Neurobiol. Dis. 42, 360-367 (2011).

105. Lee, H. J. et al. Assembly-dependent endocytosis and clearance of extracellular $\alpha$-synuclein. Int. J. Biochem. Cell. Biol. 40, 1835-1849 (2008).

106. Emmanouilidou, E. et al. Cell-produced $\alpha$-synuclein is secreted in a calcium-dependent manner by exosomes and impacts neuronal survival. J. Neurosci. 30, 6838-6851 (2010)

The first report that $\alpha$-syn is secreted by externalized vesicles in a calcium-dependent manner.

107. Jao, C. C., Hegde, B. G., Chen, J., Haworth, I. S. \& Langen, R. Structure of membrane-bound $\alpha$-synuclein from site-directed spin labeling and computational refinement. Proc. Natl Acad. Sci. USA 105 19666-19671 (2008)

108. Volpicelli-Daley, L. A. et al. Exogenous $a$-synuclein fibrils induce Lewy body pathology leading to synaptic dysfunction and neuron death. Neuron 72, 57-71 (2011).

109. Crews, L. et al. $\alpha$-synuclein alters Notch-1 expression and neurogenesis in mouse embryonic stem cells and in the hippocampus of transgenic mice. $J$. Neurosci. 28, 4250-4260 (2008)

110. Letarov, A., Manival, X., Desplats, C. \& Krisch, H. M. gpwac of the T4-type bacteriophages: structure, function, and evolution of a segmented coiled-coil protein that controls viral infectivity. J. Bacteriol. 187 1055-1066 (2005)

111. Ekberg, H. et al. The specific monocarboxylate transporter-1 (MCT-1) inhibitor, AR-C117977, induces donor-specific suppression, reducing acute and chronic allograft rejection in the rat. Transplantation 84 1191-1199 (2007)

112. Karlsson, J., Petersen, A., Gido, G., Wieloch, T. $\delta$ Brundin, P. Combining neuroprotective treatment of embryonic nigral donor tissue with mild hypothermia of the graft recipient. Cell Transplant. 14, 301-309 (2005).

113. Karlsson, J., Emgard, M., Gido, G., Wieloch, T \& Brundin, P. Increased survival of embryonic nigral neurons when grafted to hypothermic rats. Neuroreport 11, 1665-1668 (2000)

114. Frodl, E. M., Duan, W. M., Sauer, H., Kupsch, A. \& Brundin, P. Human embryonic dopamine neurons xenografted to the rat: effects of cryopreservation and varying regional source of donor cells on transplant survival, morphology and function. Brain Res. 647 286-298 (1994)

115. Kordower, J. H., Freeman, T. B. \& Olanow, C. W. Neuropathology of fetal nigral grafts in patients with Parkinson's disease. Mov. Disord. 13, 88-95 (1998).

116. Tang, B. et al. Forkhead box protein $\mathrm{p} 1$ is a transcriptional repressor of immune signaling in the CNS: implications for transcriptional dysregulation in Huntington disease. Hum. Mol. Genet. 21 3097-3111 (2012)

117. Nonaka, T., Watanabe, S. T., Iwatsubo, T. \& Hasegawa, M. Seeded aggregation and toxicity of $\alpha$-synuclein and tau: cellular models of neurodegenerative diseases. J. Biol. Chem. 285 , 34885-34898 (2010).

118. Luk, K. C. et al. Intracerebral inoculation of pathological $\alpha$-synuclein initiates a rapidly progressive neurodegenerative $\alpha$-synucleinopathy in mice. J. Exp. Med. 209, 975-986 (2012).

119. Ban, T. et al. Direct observation of $A \beta$ amyloid fibril growth and inhibition. J. Mol. Biol. 344, 757-767 (2004).

120. Lashuel, H. A. et al. New class of inhibitors of amyloid- $\beta$ fibril formation. Implications for the mechanism of pathogenesis in Alzheimer's disease. J. Biol. Chem. 277, 42881-42890 (2002)

121. Di Giovanni, S. et al. Entacapone and tolcapone, two catechol O-methyltransferase inhibitors, block fibril formation of $\alpha$-synuclein and $\beta$-amyloid and protect against amyloid-induced toxicity. J. Biol. Chem. 285 14941-14954 (2010).

122. Masuda, M. et al. Small molecule inhibitors of a-synuclein filament assembly. Biochemistry 45, 6085-6094 (2006)

123. Porat, Y., Abramowitz, A. \& Gazit, E. Inhibition of amyloid fibril formation by polyphenols: structura similarity and aromatic interactions as a common inhibition mechanism. Chem. Biol. Drug Des. 67 27-37 (2006)

124. Ayrolles-Torro, A. et al. Oligomeric-induced activity by thienyl pyrimidine compounds traps prion infectivity. J. Neurosci. 31, 14882-14892 (2011).

125. Hirohata, M. Ono, K. Morinaga, A. \& Yamada, M. Non-steroidal anti-inflammatory drugs have potent anti-fibrillogenic and fibril-destabilizing effects for a-synuclein fibrils in vitro. Neuropharmacology 54, 620-627 (2008)

126. Bartels, T., Choi, J. G. \& Selkoe, D. J. $\alpha$-Synuclein occurs physiologically as a helically folded tetramer that resists aggregation. Nature 477, 107-110 (2011)

127. Wang, W. et al. A soluble $\alpha$-synuclein construct forms a dynamic tetramer. Proc. Natl Acad. Sci. USA 108 17797-17802 (2011).

128. Fauvet, B. et al. Semisynthesis and characterization of $\mathrm{N}$-terminally acetylated $\alpha$-synuclein: implications for aggregation and cellular properties. J. Biol. Chem. 287, 28243-2862 (2012).

129. Shaikh, S. \& Nicholson, L. F. Advanced glycation end products induce in vitro cross-linking of a-synuclein and accelerate the process of intracellular inclusion body formation. J. Neurosci. Res. 86, 2071-2082 (2008).

130. Hashimoto, M., Takeda, A., Hsu, L. J., Takenouchi, T. $\delta$ Masliah, E. Role of cytochrome $c$ as a stimulator of $\alpha$-synuclein aggregation in Lewy body disease. J. Biol. Chem. 274, 28849-28852 (1999)

131. Lashuel, H. A., Hartley, D., Petre, B. M., Walz, T. Lansbury, P. T. Jr. Neurodegenerative disease: amyloid pores from pathogenic mutations. Nature 418, 291 (2002).

\section{Acknowledgements}

The authors acknowledge grant support from the US National Institutes of Health (grants AG5131, AG18440, AG022074 and NS044233 to E.M.), the Swiss National Science Foundation (grant \#31003A_120653 to H.A.L.) and the Ecole Polytechnique Fédérale de Lausanne (European Research Council starting grant to H.A.L.)

\section{Competing interests statement}

The authors declare no competing financial interests. 